\title{
STAND-ALONE SOFTWARE AS A MEDICAL DEVICE: QUALIFICATION AND LIABILITY ISSUES
}

10.36740/WLek202010134

\author{
Pashkov Vitaliii, ${ }^{1,2}$, Harkusha Andrii ${ }^{1,2}$, Harkusha Yevheniia ${ }^{2}$ \\ 'DEPARTMENT OF CIVIL, COMMERCIAL AND ENVIRONMENTAL LAW, POLTAVA LAW INSTITUTE, POLTAVA, UKRAINE \\ ¿LABORATORY FOR THE STUDY OF NATIONAL SECURITY PROBLEMS IN THE FIELD OF PUBLIC HEALTH, KHARKIV, UKRAINE
}

\begin{abstract}
Through a broad literature review, analysis of EU, USA and Ukraine regulation acts, scientific researches and opinions of progressive-minded people in this sphere this paper provide a guide to understanding the essence of stand-alone software as a medical device and specifics of its regulation. It is based on dialectical, comparative, analytic, synthetic and comprehensive methods.
\end{abstract}

KEY WORDS: apps, software, medical devices, medical devices directive, medical devices regulation

Wiad Lek. 2020;73(10):2282-2288

\section{INTRODUCTION}

The number of people that using digital tools (including software applications), has significantly increased in the past few years - spreading of the Internet of Things (IoT) and Internet of Medical Things (IoMT) is a global and unstoppable trend. The range of apps designed for checking health or lifestyle, or for assistance with a disease overcoming has also increased considerably for the last 3-5 years.

There is a wide range offer of such tools, apps now can measure our physical fitness, physical conditions, give health tips, analyze physiological data, and calculate the dosing of medicines etc. The majority of those are free of charge and thus are looking interesting to potential customer, but thus they are poses significant threat because of being healthcare-related. Considering that, the abovementioned sphere is accordingly got significant scientific attention [2-4] and partly was the scope of our previous researches [5-8].

But there is one huge question remains: when such devices have to be qualified as a typical (regular) software application and when they have to be qualified namely as a medical device? And if the app is a medical device in fact, then how it has to be placed on the market and what is the liability for breaking such rules and regulations? Those matters will be in the focus of this particular research.

\section{MATERIALS AND METHODS}

Through a broad literature review, analysis of EU, USA and Ukraine regulation acts, scientific researches and opinions of progressive-minded people in this sphere this paper provide a guide to understanding the essence of stand-alone software as a medical device and specifics of its regulation. It is based on dialectical, comparative, analytic, synthetic and comprehensive methods.

\section{REVIEW AND DISCUSSION}

Scope of the current study. First of all, it is important to define that stand-alone software is a software that is not incorporated into a medical device, thus in this article we will analyze only within the scope software applications leaving behind most of the hardware-related issues.

What's the definition of a medical device now? We will compare the most comprehensive ones in their appliance to Ukraine (Table 1).

To summarize all the above mentioned, software application is classified as a medical device when it is developed for the medical purpose, particularly:

- diagnosing, curing, mitigating, treating, alleviating, compensating or preventing an injury or a disease;

- providing means and suggestions for mitigation of a disease;

- providing information for determining compatibility, detecting, diagnosing, monitoring or treating physiological conditions, states of health, illnesses or congenital deformities;

- aiding diagnosis, screening, monitoring, determination of predisposition; prognosis, prediction, determination of physiological status [12].

Thus, the main criteria of qualification software application as a medical device - is intended purpose of its further use by the customer. And the real intended purpose is identified in accordance with the manufacture's information 
Table 1. What's the definition of a medical device now?

\begin{tabular}{|c|c|}
\hline EU & $\begin{array}{l}\text { a'medical device' means any instrument, apparatus, appliance, software, material or other article, whether used alone } \\
\text { or in combination, including the software intended by its manufacturer to be used specifically for diagnostic and/or } \\
\text { therapeutic purposes and necessary for its proper application, intended by the manufacturer to be used for human } \\
\text { beings for the purpose of: } \\
\text { diagnosis, prevention, monitoring, treatment or alleviation of disease, } \\
\text { diagnosis, monitoring, treatment, alleviation of or compensation for an injury or handicap, } \\
\text { investigation, replacement or modification of the anatomy or of a physiological process, control of conception, } \\
\text { and which does not achieve its principal intended action in or on the human body by pharmacological, immunological } \\
\text { or metabolic means, but which may be assisted in its function by such means [9]. }\end{array}$ \\
\hline USA & $\begin{array}{l}\text { a 'medical device' means an instrument, apparatus, implement, machine, contrivance, implant, in vitro reagent, or } \\
\text { other similar or related article, including a component part or accessory which is: recognized in the official National } \\
\text { Formulary, or the United States Pharmacopoeia, or any supplement to them, } \\
\text { intended for use in the diagnosis of disease or other conditions, or in the cure, mitigation, treatment, or prevention of } \\
\text { disease, in man or other animals, or } \\
\text { intended to affect the structure or any function of the body of man or other animals, and which does not achieve its } \\
\text { primary intended purposes through chemical action within or on the body of man or other animals and which is not } \\
\text { dependent upon being metabolized for the achievement of any of its primary intended purposes [10]. }\end{array}$ \\
\hline Ukraine & the definition is the same that in the EU considering our trend of harmonization with EU-law [11]. \\
\hline
\end{tabular}

on labelling, instructions for use or promotional materials (e.g. website, information in App Store, Google Play) regarding the specific product.

Also, a lot of authorities both in EU and US provided their guidelines regarding identifying software applications as a medical device with applicable decision-making tree (see in Attachment A and B to this article) or with stepby-step explanations and examples, particularly:

- MEDICAL DEVICES: Guidance document; Qualification and Classification of stand-alone software, issued by European Commission [13];

- Policy for Device Software Functions and Mobile Medical Applications; Guidance for Industry and Food and Drug Administration Staff, issued by U.S. Department of Health and Human Services Food and Drug Administration [14];

- Guidance: Medical device stand-alone software includingapps (including IVDs), issued by Ministry of Health, Welfare and Sport, Netherlands [15];

- Guidance: Medical device stand-alone software including apps (including IVDMDs) v1.05, issued by Medicines \& Health care products Regulatory Agency, UK [16];

- Guide to Placing Medical Device Standalone Software on the Market, issued by Health Products Regulatory Authority, Ireland [17];

- Guidance on "Medical Apps", issued by Federal Institute of Drugs and Medical Devices [18] and others.

The new Medical Device Regulation [24], published in April 2017 and replaced the MDD in May 2020, puts more emphasis on software. General-purpose software or software for life style and well-being purposes is explicitly excluded from the MDR. Compared to the MDD, there is an additional classification rule (rule 11) for software in the MDR, that covers other types of software, e.g. for clinical decision support.

Rule 11. Software intended to provide information which is used to take decisions with diagnosis or therapeutic purposes is classified as Class II a, except if such decisions have an impact that may cause:

- death or an irreversible deterioration of a person's state of health, in which case it is in Class III; or

- a serious deterioration of a person's state of health or a surgical intervention, in which case it is classified as Class II b.

Software intended to monitor physiological processes is classified as Class II a, except if it is intended for monitoring of vital physiological parameters, where the nature of variations of those parameters is such that it could result in immediate danger to the patient, in which case it is classified as Class II b.

All other software is classified as Class I.

It is also worth noting that this year Ministry of Health of Ukraine has developed and issued the Methodical recommendations named «Classification of medical devices» [19], but there is nothing about qualification/classification of software applications as a medical device. It is strange considering the time of its issuing and general vector of digitalization in different spheres of national practice.

Most of guidance provides examples of software functions, some of which are mobile apps, that does not consider to meet the definition of a medical device and, therefore, are not medical apps, particularly: 1) the monitoring of general fitness, general health and general wellbeing is not usually considered to be a medical purpose; 2 ) it just reproduces a paper document in digital format; 3 ) it is down to the health care professional to make the decisions based on the advice displayed; 4) it just follows the path of a procedure/treatment - there are no decisions - may provide information; 5 ) it has decision points, options may be explained but the health care professional decides which path to take; 6) it offers only lifestyle treatment choices or referral advice. [15]

The documents above demonstrate that this field is enough regulated, precise, and transparent. Still, the investigation of the application software market, that has been performed by order and at the expense of Dutch 
Table 2. Categories used for identification of apps

\begin{tabular}{cc}
\hline Google Play & Health \& fitness \\
\hline Apple Store & Health \& fitness, Medicine \\
\hline Zorglnnovatie & $\begin{array}{c}\text { eHealth, mHealth/apps (various } \\
\text { combinations/spelling) }\end{array}$ \\
\hline DigitaleZorgGids & Products \\
\hline Website ICT \& Health & All news items related to apps \\
\hline
\end{tabular}

Ministry of Health, Welfare and Sport, Pharmaceuticals and Medical Technology Department «Apps under medical device legislation" [20], demonstrates that it is not the case. There are a lot of gaps and contradictions that need to be fixed.

\section{BRIEF DETAILS OF THE INVESTIGATION}

Term of the investigation. An inventory of apps was conducted in the period November 2017 - February 2018.

Scope. The purpose was to undertake an explorative study to investigate the type of eHealth products currently available, the classification of these products under current (MDD) and future regulation (MDR), and the value of available decision trees in the process of classification. As eHealth is very broad, this study was limited to apps.

Methods. Apps were searched for in specific categories for the different websites, as shown in Table 2.

\section{CLASSIFICATION AND CATEGORIZATION CLASSIFICATION}

The authors determined whether apps were medical devices, based on the definition in the MDD, as the decision trees are also based on the definition in the MDD. This decision was based on the publicly available information on the app, most often on the website. This information often contained concise information on the app. No additional information on the app was requested from the manufacturer for the classification. Each app was classified by one assessor and checked by a second assessor. It was checked whether there was a CE-mark explicitly mentioned, either on the website, on pictures of the app or in the app itself, when downloaded and opened.

Results: Medical devices or not. In total, 271 apps were identified. Of these 271 apps, 56 (21\%) were considered as medical devices based on the available information. The remaining apps (79\%; 215 apps) were not considered to be medical devices, i.e. without a direct medical purpose. For example, an app only measuring heart rate, e.g. a sports app, is not considered as a medical device.

No medical device, but CE-mark applied. For four apps not classified as medical devices, a CE mark was identified.

Medical device, but no CE-mark noticed. For 36 apps of the 56 apps classified as medical devices, CE-marks could not be found, it is possible that the CE mark has been applied, but this was not mentioned in the information assessed for this study [20].
The results of this study shows that despite of a lot of guidelines and decision-making trees/step-by-step explanations etc., there are a lot of software applications that in fact are medical devices, but does not have appropriate level of protection for customers (were not developed in accordance with medical device regulation) and at the same time there are software applications that were not correctly qualified as a medical devices by manufactures. Thus, we can conclude that the problem of qualification software applications as a medical device is still valid.

There is another issue that, from our point of view, was discovered by the study above. The situation, when a lot of different software applications with medical purpose are available at the market without compliance with relevant regulation, demonstrates that there is no effective control on their market-placement from the authorities. From our perspective, the difficulties here are arising from the nature of software application as a product and the way of its distribution. Usually software apps are distributing online via manufacture's website or via relevant stores/ marketplaces such as App Store, Google Play etc. And if in case of usual medical devices that are available at the offline store/pharmacy, everything is clear - if the store/ pharmacy is situated on someone countries territory, a medical device is available for customers from that particular territory. As a result, this medical device has to be marked and compliant with that legislations, controlled by the relevant authorities of this country and is "under control" in general. In case with software applications this scenario obviously does not work.

It seems logical, that the software application developed for EU market has to be CE-marked, the one that is developed for USA - to comply with applicable labeling regulations found in 21 CFR Part 801 for medical devices, designed for Ukraine - to be marked with national mark of conformity. But software application for a non-European/ USA/Ukraine market might be available for customers from those countries. It is hard to restrict the ability to download and use the application from anywhere (both legally and technically). The fact, that some software applications available on the internet can be accessed anywhere, makes it more difficult to regulate what particular legislation/rules/guidance such software application has to be complied with. And what factors should be taken into consideration for deciding to what market this software application was developed: localization of software application's website/product features, description (language of the product description, of the site, of legal documents, 
of customer support etc.); direct targeting of software applications for some country (buying traffic for example); some amount of customers who buys the software application from some territory or something else. And who is the relevant authority for taking such decision? And if this "gray area" for other software applications does not look crucial, for software applications that has medical purpose and are in fact medical devices, this looks like a huge gap, considering possible risks and impact on human health.

It is noteworthy that for one of the apps, founded during this study "Apps under medical device legislation», there was a disclaimer: «No medical advice». «If you access this application from other locations (and outside the USA), you are responsible for compliance» [20]. There is also a note in the Germany Guidance on «Medical Apps» which pointed that declarations e.g. a statement in the App Store «This is not a medical device» do not circumvent the afore-mentioned criteria and are not considered in the BfArM's decisions pursuant to Section 13 MPG if an intended medical purpose is stated or implied by the manufacturer in labelling, instructions for use or promotional materials [18].

Taking into account the foregoing, we believe that in case we are talking about human health, disclaimers, or guidance, that are currently unconstrained or has informational status, is not enough for protecting human rights. For that we need a system of precise and strict regulations to be taken in place.

Lack of certainty in market-placement of software applications that are medical devices along with absence of adequate level of control of authorities arise the other issue - difficulties in prosecution for, cause it is unclear who is the subject of liability (definitions of manufactures of medical devices is not common and can be varied from country to country); authority of which country is relevant and empowered body for taking a decision in each particular case; what legislation with regard to liability is applicable for software applications that are medical devices and are available worldwide.

Also, it has to be pointed out that in Ukraine there is only administrative liability for «Failure to comply with the legal requirements of officials of the central executive body that implements the state policy in the field of standardization, metrology, and metrological activities and technical regulation» [21]. The Criminal Code of Ukraine [22] does not provide for liability for the falsification of medical devices. This is a violation of Ukraine's international legal obligations, which have ratified the Council of Europe Convention on the counterfeiting of medical products and similar crimes involving threats to public health [23]. Those gaps in legal regulation, including absence of specialize law on medical devices creates unfavorable conditions of effective protection for Ukrainian customers, that can freely download software applications with medical purpose from most of the popular stores and marketplaces.

\section{CONCLUSION}

Summarizing the above mentioned, it is feasible to make the following conclusions:
1) The range of software applications for the health sector has increased significantly in the past years. There is a wide range of such tools on offer, ranging from tips for quit smoking or a tool for measuring heart rate to help with mental health problems. The majority of health and lifestyle apps are free of charge;

2) Despite of existance of a lot of guidance and decision-making trees, explanations, issued by relevant authorities in a lot of countries, the border between health and fitness apps and medical devices is still not clear for manufactures;

3) There are a lot of software applications with medical purpose available at the market that are incompliant with the relevant regulations;

4) There is no adequate level of control from the authority's perspective with regard to manufacturing and placing of software applications that could be qualified as a medical device at the market;

5) There are difficulties in identifying what is the exact legislation that has to be applied to software applications that are medical devices, considering their worldwide availability, unclear procedure and criteria for defining market to which particular software application was developed;

6) Ukrainian customers has low level of protection, cause the gaps in our national law regulation with regard to medical devices (absence of special guide of identifying software applications as a medical devices and proper level of liabilities for manufactures as well as special law that establish legal basis for medical devices manufacturing).

Considering those conclusions, it looks like just simple explanation and guidances (which are only recommendation/information) issued separately by each country is not enough for regulating the sphere of manufacturing software applications that are medical devices. Considering the global nature of this matter, specifics of the products, that could be downloaded online worldwide and bearing in mind possible implication on human 's body, health and life, it sounds reasonable to develop and adopt international, legally binding regulation that will cover building of software applications with medical purpose and to establish uniform rules for their qualifications and liabilities for non-compliance.

\section{REFERENCES}

1. Mobile app usage - Statistics \& Facts. See at: https://www.statista. com/topics/1002/mobile-app-usage/

2. Carroll N., Travers M., Richardson I. "Evaluating multiple perspectives of a connected health ecosystem", 9th International Conference on Health Informatics (HEALTHINF), Rome, 2016, 21-23 February.

3. O'Leary P., Carroll N., Clarke P., Richardson, I."Untangling the complexity of connected health evaluations", IEEE International Conference on Healthcare Informatics2015 (ICHI 2015), Dallas, 2015, 21-23 0ctober.

4. Richardson I." Connected health: people, technology and processes", Lero Technical Report Series Lero-TR-2015-03, University of Limerick, 2015.

5. Pashkov V., Kotvitska A., Harkusha A. Legal regulation of the production and trade of medical devices and medical equipment in the $\mathrm{EU}$ and US: experience for Ukraine. Wiad. Lek. 2017;70 (3 pt 2):614-618. 
6. Vitalii Pashkov, Andrii Harkusha: Certain aspects on medical devices software law regulation. Wiad. Lek. 2016; 6: 765-767.

7. Vitalii Pashkov, Nataliya Gutorova, Andrii Harkusha, Medical device software: defining key terms. Wid. Lek. 2016; 6: 813-817.

8. Hutorova N., Pashkov V., Harkusha A. Virtual augmented reality software in medical rehabilitation: key legal issues. Acta Balneologica. 2018;2 (152):55-61

9. Council Directive 93/42/EEC of 14 June 1993 concerning medical devices. 0J L 169, 12.7.1993. Amended by Directive 2007/47/EC of the European Parliament and of the Council of 5 September 2007. 0J L 247, 21.9.2007

10. FDA. Medical Device Overview. See at: https://www.fda.gov/industry/ regulated-products/medical-device-overview\#What $\% 20$ is $\% 20 a \% 20$ medical\%20device

11. Postanova Kabinetu Ministriv Ukrainy vid 2.10.2013 p. № 753 «Pro zatverdżennia tekhnichnogo reglamentu shchdo medychnych wyrobiv» https://zakon.rada.gov.ua/laws/show/753-2013-\%D0\%BF

12. Marion Lepmets / WHAT IS SOFTWARE AS A MEDICAL DEVICE? 23 Nov. 2016. See at: https://softcomply.com/is-my-software-a-medicaldevice/

13. EUROPEAN COMMISSION, DG Internal Market, Industry, Entrepreneurship and SMEs, MEDICAL DEVICES: Guidance document; Qualification and Classification of stand-alone software, MEDDEV 2.1/6, July 2016

14. Policy for Device Software Functions and Mobile Medical Applications Guidance for Industry and Food and Drug Administration Staff. See at: https://www.fda.gov/media/80958/download

15. MHRA. Guidance: Medical device stand-alone software including apps (including IVDs). Version 1.04, September 2017. See at: https:// assets.publishing.service.gov.uk/government/uploads/system/ uploads/attachment_data/file/890025/Software_flow_chart_Ed_106_FINAL.pdf

16. Guidance: Medical device stand-alone software including apps (including IVDMDs) v1.05, issued by Medicines \& Health care products Regulatory Agency, UK. See at: https://www.gov.uk/government/ publications/medical-devices-software-applications-apps

17. Guide to Placing Medical Device Standalone Software on the Market, issued by Health Products Regulatory Authority, Ireland. See at: https:// www.hpra.ie/docs/default-source/publications-forms/guidancedocuments/sur-g0040-guide-to-placing-medical-device-standalonesoftware-on-the-market-v1.pdf

18. BfArM. Guidance on "Medical Apps". See at: https://www.bfarm.de/EN/ MedicalDevices/Differentiation/MedicalApps/_artikel.html
19. Metodychni rekomendacii "Klasyfikacia medychnykh wyrobiv" 2020, Zatverdzheni Nakazom Ministerstva Okhorony Zdorovia Ukrainy vid 22.01.2020 № 142. See at: https://moz.gov.ua/uploads/3/16105dn_20200122_142_dod_1.pdf

20. RIVM Letter report 2018-0083 A. van Drongelen et al. Apps under the medical devices legislation. See at: https://www.rivm.nl/bibliotheek/ rapporten/2018-0083.pdf

21. Kodeks Ukrainy pro administratyvni pravoporushennia, st. 188-9. See at: https://zakon.rada.gov.ua/laws/show/80731-10

22. Kryminalnyi kodeks Ukrainy. See at: https://zakon.rada.gov.ua/go/2341-14

23. Council of Europe Convention on the counterfeiting of medical products and similar crimes involving threats to public health. See at: https://www.coe.int/en/web/conventions/full-list/-/conventions/ rms/090000168008482f

24. 10 facts you need to know about the MDR as a medical software manufacturer. See at: https://decomplix.com/medical-software-mdr/

\section{ORCID and contributionship:}

Pashkov Vitalii: 0000-0001-9489-7768 ${ }^{A, B, E, F}$

Harkusha Andrii: 0000-0001-5266-3007 B,D,F

Harkusha Yevheniia: 0000-0002-9932-8756 ${ }^{\text {B,D,F }}$

\section{Conflict of interest:}

The Authors declare no conflict of interest

\section{CORRESPONDING AUTHOR}

\section{Vitalii M. Pashkov}

Department of Civil, Commercial and Environmental Law,

Poltava Law Institute, Poltava, Ukraine

tel: +380666931651

e-mail: v.pashkov26.06@ukr.net

Received: 10.06 .2020

Accepted: 07.09 .2020

A - Work concept and design, B - Data collection and analysis, C - Responsibility for statistical analysis, D-Writing the article, $\mathbf{E}$-Critical review, $\mathbf{F}$ - Final approval of the article 


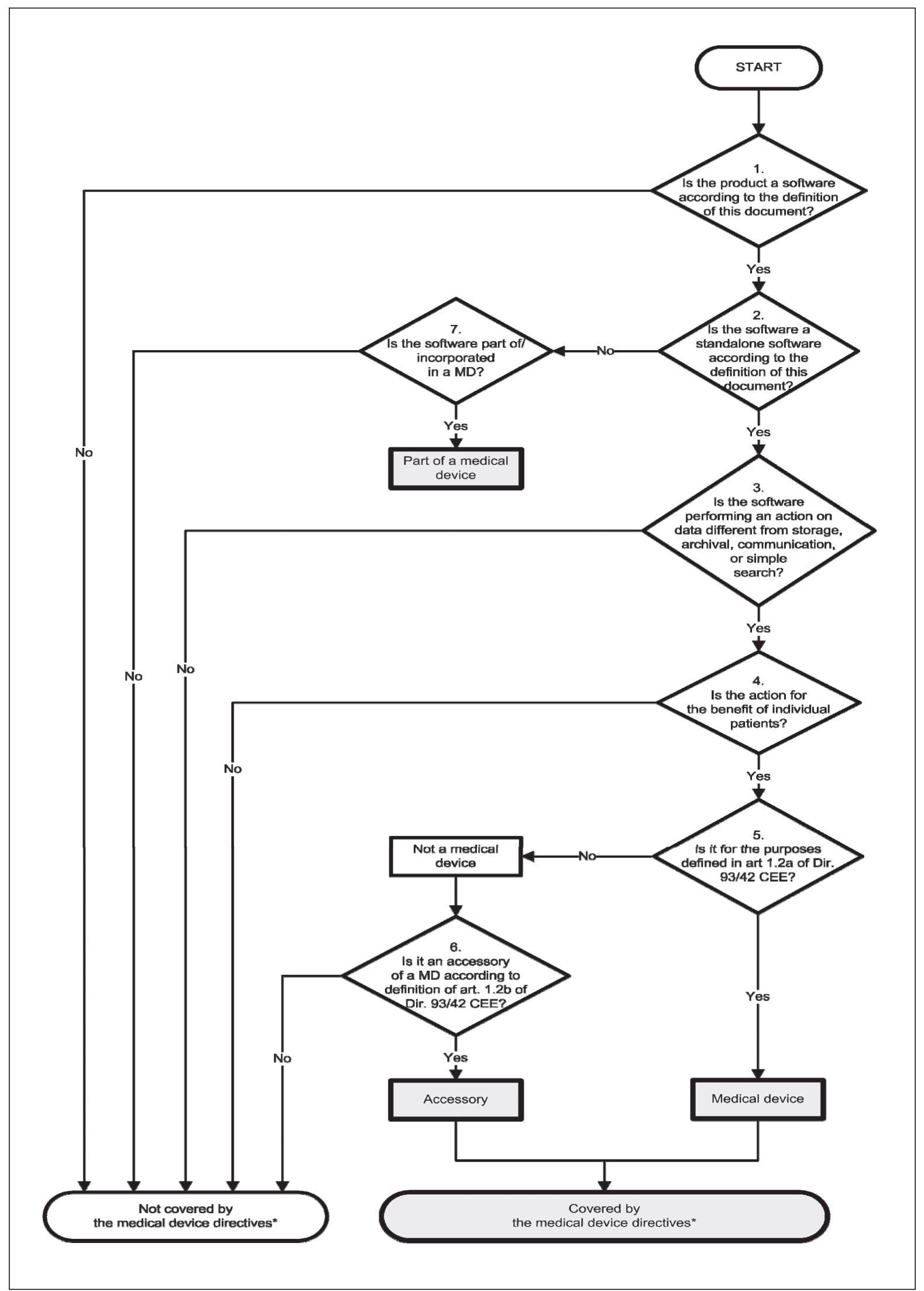

Attachment A. 


\section{2.}

Medicines \& Healthcare products

Guidance: Medical device stand-alone software including apps (including IVDMDs) v1.05

Regulatory Agency

From P6 - device

decision flow diagram

\section{Medical purpose}
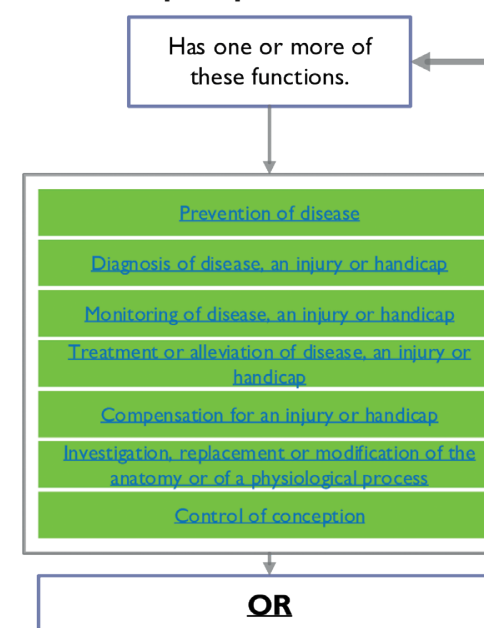

Has one of the above functions plus one of the following and looks at in vitro data:

Concerning a physiological or pathological state
Concerning a congenital abnormality
Io determine the safety and compatibility with
potential recipients
Io monitor therapeutic measures

Check what the

intended purpose is

(to PII).

Has a medical

purpose.

(return to P6)

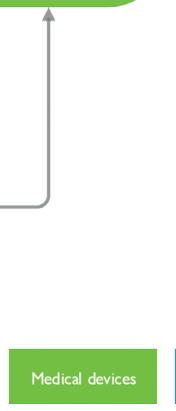

: MHRA

Multipurpose product

A multipurpose product, e.g. a spreadsheet program such as

MS Excel, which is used occasionally in a medical environment

is normally not considered to be a medical device, unless a

specific medical intended purpose is assigned to it.

\section{Attachment B.}

